\title{
Microstructural evolution of fine-grained layers through the firn column at Summit, Greenland
}

\author{
R. LOMONACO, M. ALBERT, I. BAKER \\ Thayer School of Engineering, Dartmouth College, Hanover, New Hampshire 03755-8000, USA \\ E-mail: ian.baker@dartmouth.edu
}

\begin{abstract}
We present a microstructural characterization of fine-grained layers from the top $90 \mathrm{~m}$ of firn from Summit, Greenland, performed using a combination of scanning electron microscopy techniques including secondary electron imaging, energy-dispersive spectroscopy and electron backscattered patterns, and X-ray microcomputed tomography. The impurities in the firn, both soluble impurities and dust particles, were found largely in the grain interiors. Both $c$ - and a-axis pole figures do not show strong evidence of a preferred orientation of the grains even at the bottom of the firn column. The firn structure became increasingly anisotropic with vertical alignment in the top $3 \mathrm{~m}$, probably due to vapor transport associated with dry-snow metamorphism. The anisotropy decreases below this level until at $\sim 50 \mathrm{~m}$ the average firn structure is close to isotropic. In the near surface, the level of anisotropy is weaker than at Hercules Dome, Antarctica, confirming that differences in accumulation rates and temperatures leave enduring evidence in the structure of the firn. The fraction of closed-off pores is relatively low until $\sim 65 \mathrm{~m}$; below that it rises through the end of our sampling at $90 \mathrm{~m}$. Our microstructure measurements on the microscale are consistent with in situ firn-air sampling measurements on a decimeter scale, both indicating the existence of the lock-in zone starting near $69 \mathrm{~m}$ depth, and pore close-off at $81 \mathrm{~m}$ at this site.
\end{abstract}

\section{INTRODUCTION}

Firn is porous multi-year snow consisting of ice and air that comprises the top $60-100 \mathrm{~m}$ of polar ice sheets. The structure of firn is important to atmospheric chemistry (e.g. Dominé and others, 2008), it affects remotely sensing data (e.g. Li and others, 2008) and its porous nature permits transport of air down to pore close-off, below which the air trapped in bubbles in the ice holds evidence of ancient atmospheric composition (e.g. Schwander and others, 1988, 1997; Sowers and others 1992; Bender and others, 1997). Polar firn is often strongly layered due to seasonal differences in its formation processes (e.g. Alley, 1987, 1988). In this paper, we focus on changes with depth in finegrained layers below $20 \mathrm{~m}$ in the firn; these layers are often thicker and more laterally homogeneous than coarsegrained layers, and provide a good starting point for investigating changes due to metamorphism, sintering, compaction and pore close-off. Measuring characteristics of the evolution of the fine-grained layers is a first step toward our broader objective of understanding microstructure, layering and gas transport, and other phenomena through the entire firn column.

For many years, preservation of snow and firn structure for characterization has been by infiltration with dimethyl phthalate, sectioning the resulting composite and examining the two-dimensional (2-D) sections optically (e.g. Davis and others, 1996; Rick and Albert, 2004; Courville and others, 2007). This technique preserves pore geometry in transporting snow from the field to the laboratory and has been widely used in seasonal snow. Three-dimensional (3-D) imaging of near-surface firn that has been preserved in dimethyl phthalate, transported to the laboratory and imaged using X-ray computed microtomography shows promising results in some cases (e.g. Heggli and others, 2009). However, pore fillers are not useful deep in the firn where constricted pore space limits infiltration of the dimethyl phthalate.
In recent years, micro X-ray computed tomography (micro-CT) imaging has been used to provide a higherresolution view of the 3 -D structure and the internal surface of both natural and artificial snow, including laboratory studies of temperature gradient metamorphism (Coléou and others, 2001; Lundy and others, 2002; Flin and others, 2003, 2004; Freitag and others, 2004; Schneebeli and Sokratov, 2004; Kaempfer and others, 2005). Lomonaco and others combined micro-CT imaging with scanning electron microscope (SEM) observations (see below) to examine firn from various sites of the 1999 US International Trans-Antarctic Scientific Expedition (ITASE) campaign (Lomonaco and others, 2008) and from Summit, Greenland (Lomonaco and others, 2009), while Hörhold and others (2009) utilized the technique in a detailed study of the first $15 \mathrm{~m}$ of firn from Hercules Dome obtained during the 2002 US ITASE campaign. X-ray tomographic studies are of particular benefit because of their non-destructive nature and the high contrast provided between ice and air.

While X-ray tomography can be used to visualize the pore size and the ice matrix, currently it is not possible to use this technique to image microstructural features such as microimpurities and filaments, and techniques for producing grain boundaries have recently been identified (e.g. Ludwig and others, 2009). The 2-D microstructure of firn and ice has been characterized by holding specimens in a cold stage and examining them using a SEM (Cullen and Baker, 2001, 2002; Baker and Cullen, 2002; Iliescu and others, 2002; Baker and others, 2003; Dominé and others, 2003; Obbard and others, 2003). The combination of these two techniques can provide insight into both the microstructural transformation and natural sintering process in both 2-D and 3-D. The use of a SEM at higher accelerating voltages $(>10 \mathrm{kV})$ also provides opportunities to determine both the chemistry of soluble impurities and dust particles using energydispersive X-ray spectroscopy (EDS) (Cullen and Baker, 
2001, 2002; Baker and Cullen, 2002; Baker and others, 2005), and the orientations of the ice crystals using electron backscattered patterns (EBSPs) (Iliescu and others, 2004; Baker and others, 2005; Obbard and others, 2006).

This paper presents a detailed characterization of finegrained layers in firn from the ice-sheet surface to just beyond pore close-off in $90 \mathrm{~m}$ of a core extracted from Summit, Greenland, during the 2007 field season. The firn-core site was located at $72^{\circ} \mathrm{N}, 38^{\circ} \mathrm{W}$ where the mean annual snow accumulation rate was $0.221 \mathrm{~m}$ w.e. $\mathrm{a}^{-1}$ over the 460 years that preceded core drilling (personal communication from J. McConnell, 2010). Micro-CT imaging and SEM observations are paired in order to understand the evolution of the 2-D and 3-D properties with depth. The combination of these two techniques is particularly powerful for microstructural characterization of firn and is made possible because microCT imaging is nondestructive, thus allowing the same specimen to be examined subsequently in the SEM (Lomonaco and others, 2008). Pore fraction, SMI and surface-areato-volume ratio are tabulated from 3-D reconstructions while crystallographic texture and micro-impurity composition and location are determined by SEM analysis.

\section{EXPERIMENTAL METHODS}

One hundred fine-grained core segments were examined from the top $90 \mathrm{~m}$ of a core retrieved from Summit. The core was stored in insulated boxes in a cold room maintained at $-29^{\circ} \mathrm{C}$ at the US Army Cold Regions Research and Engineering Laboratory in Hanover, New Hampshire, USA, for $\sim 8$ months before the measurements were made. Core segments were $8 \mathrm{~cm}$ in diameter and $2-10 \mathrm{~cm}$ in length. Each specimen was sectioned perpendicular to the core axis from a nearcenter position. The final dimensions of the specimens were $10 \mathrm{~mm} \times 10 \mathrm{~mm} \times 15 \mathrm{~mm}$ high. Each core segment was sectioned into one to three specimens. Specimens were either used for immediate observation or sealed in a small container stored in $\mathrm{a}-29^{\circ} \mathrm{C}$ cold room to await analysis.

First, a SkyScan 1172 micro-CT, equipped with a homebuilt cold stage that utilizes cold carbon dioxide sublimating from dry ice, was used to image the specimens. With the imaging lasting $\sim 7 \mathrm{~min}$, the samples were subject to a temperature gradient but the time was not sufficiently long to significantly affect the samples. Later, a cold-room adapted SkyScan 1172 located in $\mathrm{a}-10^{\circ} \mathrm{C}$ room was used for imaging. The specimen rotates in the micro-CT between the X-ray source and a camera in steps of $0.7^{\circ}$ for $180^{\circ}$, producing a set of 265 projection images. A resolution of $15 \mu \mathrm{m}$ and a long working distance were used during data acquisition.

The data were reconstructed using the SkyScan program suite. A series of processing techniques including Gaussian smoothing, ring artifact reduction and beam-hardening correction were applied. Of these corrections, beam hardening is the most important. This parameter corrects for polychromatic X-ray attenuation artifacts; low-energy X-rays attenuate on the exterior of the sample while high-intensity $\mathrm{X}$-rays pass through the entire sample. The attenuation gradient produces a false contrast effect, producing a sample that appears to have a very dense exterior and a less dense interior. Thus, the beam-hardening correction is needed to reduce the noise in the image. All these tools were employed to ensure minimal reconstruction artifacts. Image reconstruction yields a grayscale stack of 970 cross-section images correlating to the specimen.
All structural values are dependent upon thresholding, which is the most critical aspect of the micro-CT process. Therefore we use the method put forth by Kerckhofs and others (2008) to validate the micro-CT thresholds by correlating reconstructions with high-resolution 2-D binarized secondary electron images produced using an FEI field emission gun (FEG), XL-30, environmental SEM equipped with a Gatan cold stage and cryotransfer system. Threshold correlation with SEM images was performed every $10 \mathrm{~m}$ of the core to validate the threshold levels. Thresholding yields a binary representation where ice space is represented as white voxels and void space as black, or vice versa. Two 3-D models were created for every sample from a rectangular region of interest $(\mathrm{ROI})$, one that represents pore space and the other ice space. Lastly, the model was cropped into a spherical ROI $(d=8 \mathrm{~mm})$ and the microstructure values were tabulated. Properties of interest were percent ice volume, surface density, SMI, degree of anisotropy and closed-pore fraction (CPF). Imaging of multiple samples from the same layer yielded good agreement in results. However, as discussed in more detail below, the ROI $(d=8 \mathrm{~mm})$ was not large enough to give representative results of pore-space geometry in the top $\sim 20$ m of firn.

The geometrical properties are computed according to Hildebrand and Rüegsegger (1997) and Hildebrand and others (1999). Percent ice volume is tabulated based on the ratio of white voxels to total voxels in the spherical $\mathrm{ROI}$ and is used to estimate density by multiplying by the theoretical density of ice $\left(0.918 \mathrm{~g} \mathrm{~cm}^{-3}\right)$. The surface-area-to-volume ratio, $S_{\mathrm{v}}$ is the surface area of the pores inside the ROI divided by the ROI volume. The surface area of the pores inside the $\mathrm{ROI}$ is determined by the summed area of the faces of the individual voxels which lie on the border between pore and ice voxels (Hildebrand and others, 1999).

The SMI describes the convexity of the structure. Positive values of SMI are convex structures, and negative values are concave structures. For example, positive SMI for the ice phase results from ice protruding into a pore space; negative SMI is concave ice around a pore space. SMI is calculated with the use of an algorithm that artificially dilates the ice space by one voxel. SMI is calculated from

$$
\mathrm{SMI}=\frac{6\left(S^{\prime} V\right)}{S^{2}}
$$

where $V$ is the original volume of the ice matrix, $S$ is the surface area before dilation, and $S^{\prime}$ is the difference between the dilated and undilated surface areas. Specifically, values of 4,3 and -9 relate respectively to spherical structures, cylindrical structures and structures enclosing spherical holes.

The degree of anisotropy describes the symmetry of the ice matrix and identifies elongation in the vertical or horizontal directions. This is calculated with the use of an algorithm that intersects the ROI with a grid of 1600 lines spaced 13.5 pixels apart. The intersection is done discretely over a range of angles with 128 projections in all. From this a mean intercept length, MIL, is tabulated:

$$
\mathrm{MIL}=d / \mathrm{N},
$$

where $d$ is the distance the gridlines intersect with ice space and $N$ is the number of times the gridlines pass through the ice. The MIL is averaged over the gridlines in a particular direction and plotted as a vector value. This plot is referred to as the MIL pincushion. An algorithm statistically fits an 

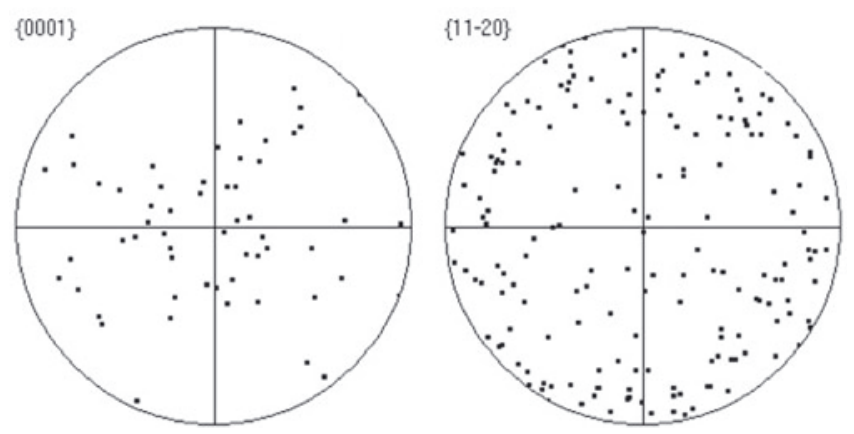

Fig. 1. Pole figure for the $c$-axis (left) and a-axis (right) of grains at $120 \mathrm{~m}$ in the firn core.

ellipsoid to the pincushion. Eigenvectors represent the principal axes of the ellipsoid, and eigenvalues are tabulated corresponding to these axes. The degree of anisotropy, DA, is obtained from

$$
\mathrm{DA}=\frac{0.5\left(E_{1}+E_{3}\right)}{E_{2}}
$$

where $E$ refers to the eigenvalues in the three principal directions as they relate to the ellipse. If $D A>1$ then the matrix is elongated horizontally, and if $\mathrm{DA}<1$ it is elongated vertically. A value of 1 is obtained from an isotropic medium.

Pore-space investigation was not possible on the firn samples at depths less than $20 \mathrm{~m}$ because the large pore spaces in that region always extended beyond the ROI. A new threshold value was used to remove very small pore spaces $(<0.1 \mathrm{~mm}$ diameter) which were most likely beamhardening artifacts described above; this was also verified by comparison of the CT images with SEM images of the same firn samples. For samples below $20 \mathrm{~m}$, we defined a CPF index to describe the interconnectedness of the pore space. The CT algorithm identifies a pore as a region of black voxels surrounded by a region of white voxels. Below $20 \mathrm{~m}$ in the firn, pore volume slowly decreases with depth, increasing the CPF index. In addition, the segregation of tortuous but connected pore space into multiple separate pore spaces also continues to occur with depth. The CPF index for each sample below $20 \mathrm{~m}$ was calculated as the ratio of the number of pores to the pore volume. The CPF index rises when the pore volume decreases and/or when the number of pores increases. Note that this index serves as an indicator of closed pores but is not an exact quantity. From visually homogeneous firn samples, five vertically adjacent samples were taken at each $5 \mathrm{~m}$ increment in depth, except at depths of 80,85 and $90 \mathrm{~m}$, where ten samples were taken. The average and standard deviation are plotted in Figure 5e (further below) as a function of depth.

The SEM was also used for EDS as described by Cullen and Baker (2001) and EBSPs as first described by Iliescu and others (2004). EBSPs were obtained from specimens at depths of 30,60,90, 100, 110 and $120 \mathrm{~m}$, while EDS data were obtained from specimens taken every $10 \mathrm{~m}$ from the surface to $120 \mathrm{~m}$.

\section{RESULTS}

EBSPs were obtained from specimens at depths of 30,60, 90, 100, 110 and $120 \mathrm{~m}$, from which pole figures were constructed. Only pole figures for the deepest region are shown (Fig. 1) since it is the most likely region to show a preferred orientation due to the deformation of ice. Figure 1 shows pole figures for both $c$ - and a-axes for the $120 \mathrm{~m}$ specimen. Each $c$-axis point represents the orientation of one independent crystal. There is not a strong indication of fabric. This was also the case for pole figures obtained from shallower depths.

Figure 2 shows typical EDS data taken from impurity spots in 110 and $80 \mathrm{~m}$ firn samples. These show $\mathrm{C}, \mathrm{Na}, \mathrm{Cl}, \mathrm{Fe}, \mathrm{Si}$ and $\mathrm{Ca}$ as impurities. The $\mathrm{O}$ peak mostly arises from the ice itself, but could also include small contributions from oxides, sulfates, nitrates and other oxygen-containing compounds if present. Other common elements that were identified were $\mathrm{K}, \mathrm{S}, \mathrm{F}, \mathrm{Al}$ and $\mathrm{Mg}$. Impurities existed in two forms, soluble impurities and dust-like particles. Soluble impurities consisted mostly of $\mathrm{Na}, \mathrm{Cl}, \mathrm{F}$ and $\mathrm{S}$, while dust-like impurities
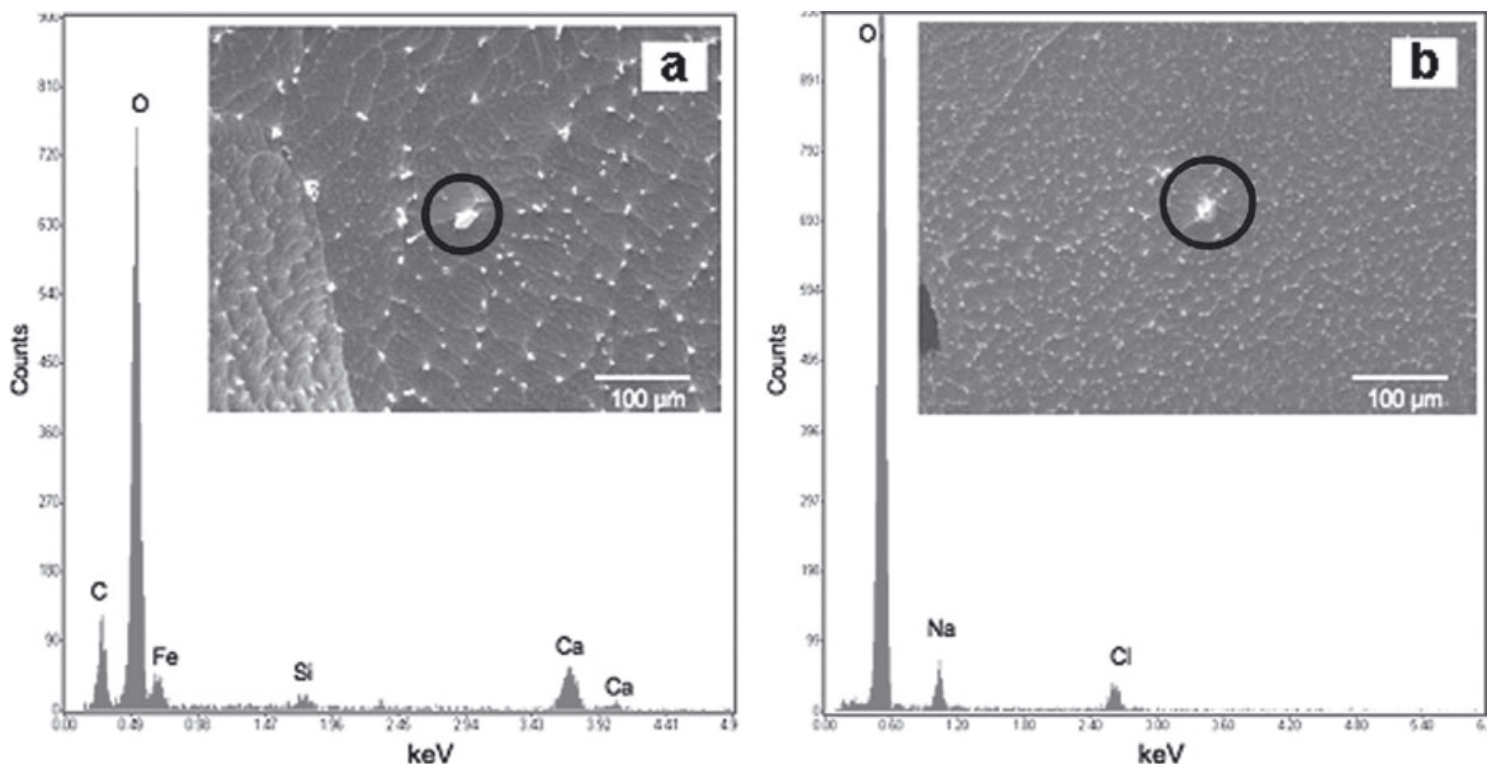

Fig. 2. EDS data and associated secondary electron images from (a) $80 \mathrm{~m}$ and (b) $110 \mathrm{~m}$ firn-core specimens. 


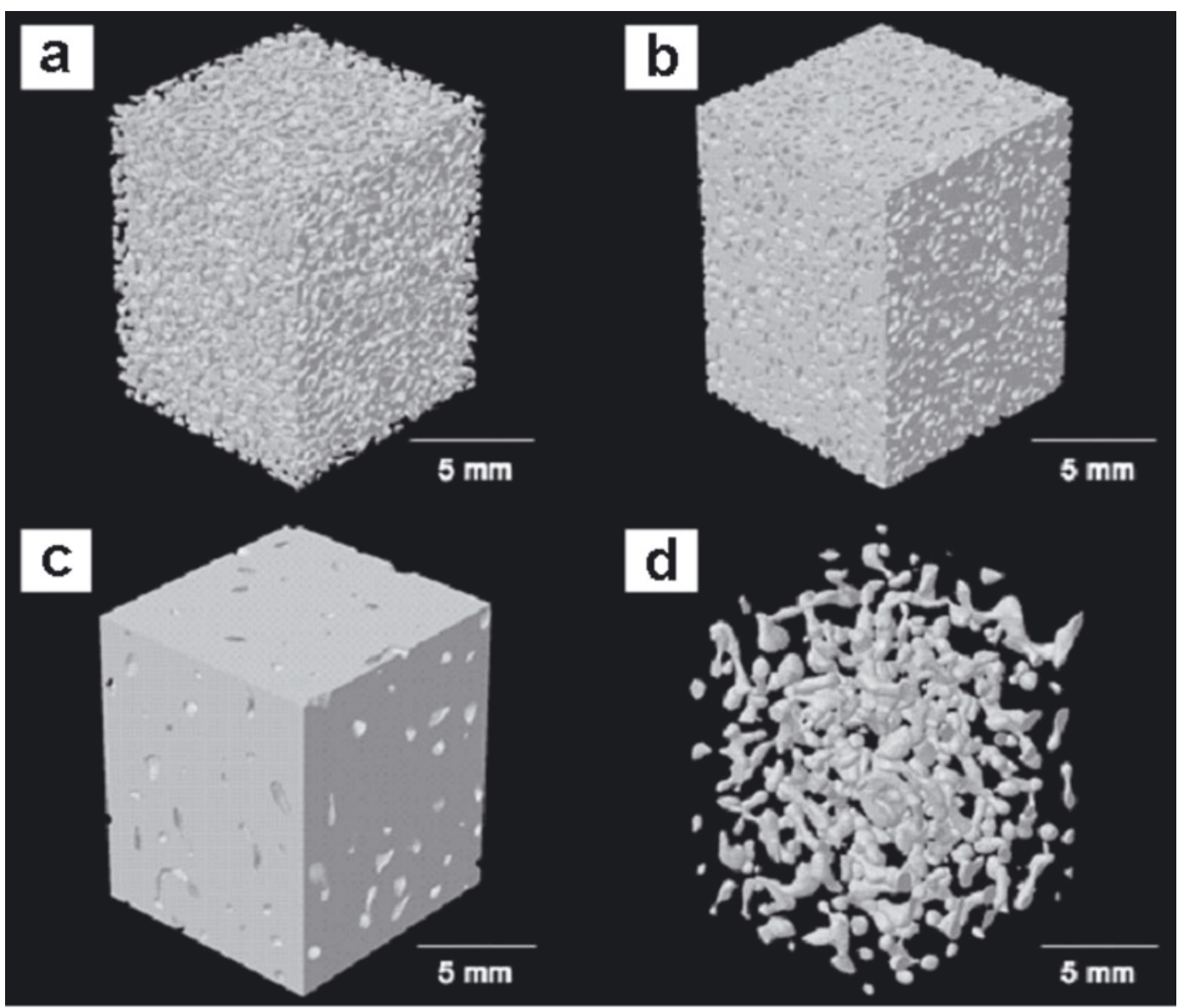

Fig. 3. Reconstructed firn cubes from $0.12 \mathrm{~m} \mathrm{(a,b)}$ and $90 \mathrm{~m}(\mathrm{c}, \mathrm{d})$ showing both ice $(\mathrm{a}, \mathrm{c})$ and pores $(\mathrm{b}, \mathrm{d})$. In $(\mathrm{a}, \mathrm{c})$ the snow is white while in $(b, d)$ the pores are shown in white. The reconstructions $(a, b)$ and $(c, d)$ are complementary.

contained $\mathrm{Fe}, \mathrm{Si}, \mathrm{Ca}, \mathrm{Al}$ and $\mathrm{K}$. Most micro-impurities were found within grains rather than in the grain boundaries. Filaments within grain boundaries were rarely observed in these firn samples. This is in contrast to observations of ice cores where impurities existed both within the grains and as filaments along the grain boundaries (Cullen and Baker, 2001, 2002; Baker and Cullen, 2002; Barnes and others, 2002; Baker and others, 2005). This difference may arise because in the deeper ice, grain boundaries sweep up impurities as they migrate, a feature demonstrated in laboratory-grown doped ice (Iliescu and Baker, 2008). Barnes and Wolff (2004) examined both surface snow and firn specimens from several depths from Dome C, Antarctica, and snow from Halley station, Antarctica, using a cold-stage equipped SEM equipped with EDS. Interestingly, they were able to detect $\mathrm{Cl}$ on the surface of the snow from Dome $\mathrm{C}$ but no impurities in the etching spots from the snow from Halley station. They found filaments at grain boundaries and triple junctions in the snow from both locations, but were unable to observe detectable impurities in some of the filaments although they likely contained impurities. In their firn specimens, filaments were observed on grain boundaries and triple junctions for specimens from 23.30 and $51.90 \mathrm{~m}$ depth, but less so in a specimen from $95.8 \mathrm{~m}$ depth even though all specimens had similar impurity levels. S, Cl and sometimes $\mathrm{Na}$ and $\mathrm{Si}$ were found in spots within the grains of the firn specimens.

Figure 3 shows examples of 3-D reconstructions of the firn core from the top and bottom of the core relating to depths of
0.12 and $90 \mathrm{~m}$ respectively. Figure $3 \mathrm{a}$ and c show the ice while Figure $3 b$ and $d$ show the pores. In Figure $3 c$ the snow is white, while in Figure $3 \mathrm{~b}$ the pores are white. While these give a 3-D picture of the structure, it is difficult to envisage the structure from such a figure. Figure 4 shows representative vertical 2-D cross-sections from the firn core every $10 \mathrm{~m}$ in which the ice is white and the pores are black. While 2-D properties do not directly translate to 3-D properties, the images are useful in seeing that a coarsening of the structure is clearly evident from 0 to $10 \mathrm{~m}$, rounding of pores can be observed from 50 to $90 \mathrm{~m}$, and the percent of ice in each image increases and pore space decreases with depth.

Figure 5a-e show 3-D microstructural data as a function of depth calculated from the micro-CT reconstructions. The density calculations (Fig. 5a), based on ice volume percent, show a sharp increase in the first $5 \mathrm{~m}$, then a more gradual increase until $90 \mathrm{~m}$ (Fig. 5a). At $90 \mathrm{~m}$ the calculated density was $0.845 \mathrm{~g} \mathrm{~cm}^{-3}$. The surface-to-volume ratio, $S_{\mathrm{v}}$ shows a rapid decrease from the surface to $4 \mathrm{~m}$ and then a steadier decrease to $90 \mathrm{~m}$ (Fig. 5b). The SMI, which describes the convexity of the pore space, shows an almost linear decrease throughout the core, with generally decreasing positive values from the surface to $20 \mathrm{~m}$, an SMI close to zero between 20 and $40 \mathrm{~m}$, and variable but increasingly negative values deeper than $40 \mathrm{~m}$ (Fig. 5c).

The degree of anisotropy from the firn-core samples shows a definite skew below a value of 1 , with a local minimum at $\sim 3 \mathrm{~m}$ (Fig. $5 \mathrm{~d}$ ). The firn generally becomes more isotropic below this, approaching a value of 1 , until at 

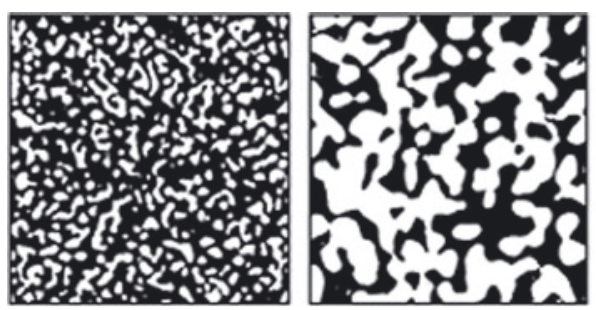

$10 \mathrm{~m}$
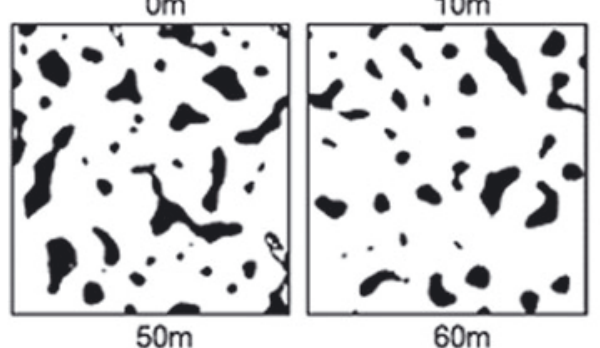

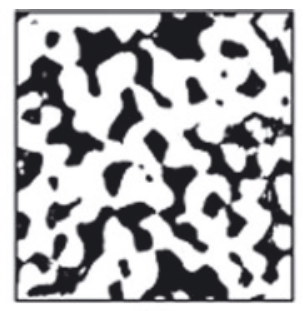

$20 \mathrm{~m}$

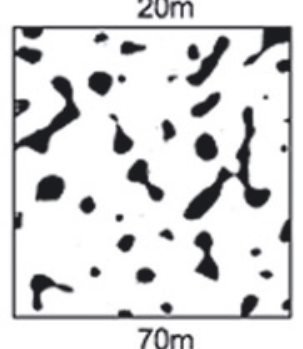

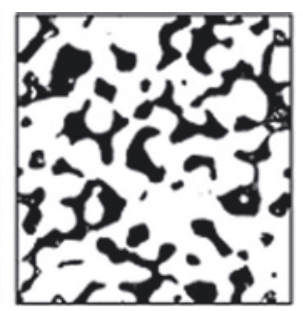

$30 \mathrm{~m}$

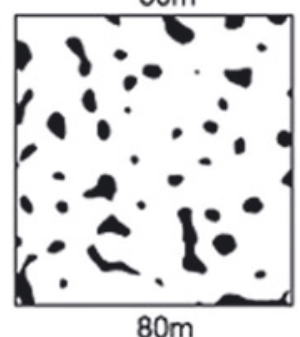

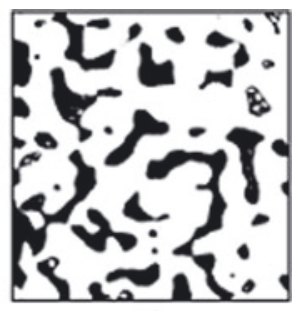

$40 \mathrm{~m}$

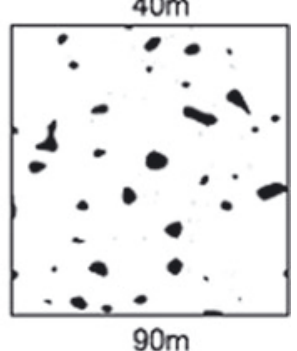

Fig. 4. Representative vertical cross sections from the micro-CT taken every $10 \mathrm{~m}$, of the firn core, in which the ice is white and the pores are black. Each image corresponds to a width of $8 \mathrm{~mm}$ on the specimen.

$\sim 20 \mathrm{~m}$ the average firn structure is close to isotropic, where it remained throughout the rest of the core.

The firn above $20 \mathrm{~m}$ depth was sufficiently porous that the small imaged sample did not contain a large number of snow grains in the ROI, so that a valid CPF index could not be calculated in that region. Values at $20 \mathrm{~m}$ and below were validated visually with the small $(d=2 \mathrm{~mm}) 3$-D model. Figure 5 e shows the values of the CPF index, along with bars to indicate one standard deviation above and below each average. The CPF index increases between 20 and $35 \mathrm{~m}$. From 35 to $65 \mathrm{~m}$ the data show that relative changes in the CPF index are within the standard deviation of the multiple samples. From 65 to $90 \mathrm{~m}$ the CPF index values increase at two different rates: one rate from 65 to $80 \mathrm{~m}$ and a second, higher rate from 80 to $90 \mathrm{~m}$.

\section{DISCUSSION}

Sintering is a dynamic process where multiple mechanisms and driving forces work in concert to densify the ice matrix present (e.g. Blackford, 2007). Swinkels and Ashby (1980) describe six main mechanisms by which sintering occurs. They are surface diffusion from a surface source, lattice diffusion from a surface source, vapor transport from a surface source, boundary diffusion from a boundary source, lattice diffusion from a boundary source and lattice diffusion from a dislocation source. It is assumed that each of these processes affects the ice matrix but that each works at a different rate depending on the driving forces present. Within this study we can account for three main driving forces: temperature gradient, overburden pressure gradient and chemical potential gradient, the latter produced by differences in local curvature. Multiple driving forces can be present at a given depth, but their effectiveness will change with depth. The following discussion outlines the leading driving forces and possible mechanisms present at each depth interval to produce the observed morphology.

In the first $3 \mathrm{~m}$ of the firn column, a large decrease in surface-to-volume ratio occurs, indicating coarsening of the ice particles. The ice in the firn has the strongest anisotropy in the top $10 \mathrm{~m}$, where the degree of anisotropy is $<1$ (Fig. 5d). A local minimum exists at $3 \mathrm{~m}$, which is consistent with recent findings at Hercules Dome (Hörhold and others, 2009) and Siple Dome, Antarctica (Albert and others, 2000). In this region, vertical structures are preferentially generated. This is to be expected from temperature-gradient-induced vapor diffusion, where material is preferentially deposited on the underside of particles (e.g. Colbeck, 1983). This growth rate increases the vertical connectivity of the particles more rapidly than horizontal connectivity.

In the region from 3 to $21 \mathrm{~m}$, continued compaction is exhibited by the decrease in both the SMI and $S_{\mathrm{v}}$. The degree-of-anisotropy values indicate that, on average, isotropy is approached at $\sim 20 \mathrm{~m}$ depth, although slightly anisotropic samples do exist below that. Because the degree-of-anisotropy value indicates that the firn evolves toward isotropy between 3 and $20 \mathrm{~m}$, it is evident that necks in the horizontal plane are created at an increasing rate in this region, where mass diffusion becomes increasingly attributed to chemical potential gradients and overburden pressure as depth increases.

These measurements agree with prior measurements made by different techniques at Summit by Alley (1987, 1988). In a recent study from an Antarctic site (Hörhold and others, 2009), the anisotropy persisted at all depths studied, i.e. to $15 \mathrm{~m}$. The presence of stronger anisotropy in the firn at Hercules Dome than at Summit is a reflection of the fact that the sites have different accumulation rates and temperatures, which causes enduring evidence in the structure of the firn (Rick and Albert, 2004; Hörhold and others, 2009).

Between 21 and $35 \mathrm{~m}$ a level of pore segregation is witnessed. A change in SMI from positive to negative values occurs, which describes a transformation from a convex to a concave ice surface, a transformation from ice particles surrounded by air to ice enclosing cavities of air. Also, the degree of anisotropy has small scatter around a value of 1 , indicating a nearly isotropic matrix. In conjunction, there is an increase in the CPF index. These values together relate to a changing ice matrix where adjacent particles coalesce through neck growth, leaving behind segregated concave pore spaces.

The next distinct region is from 35 to $65 \mathrm{~m}$. No evidence for a net change of CPF index exists in this region due to the large standard deviations. The SMI data decrease at a linear 

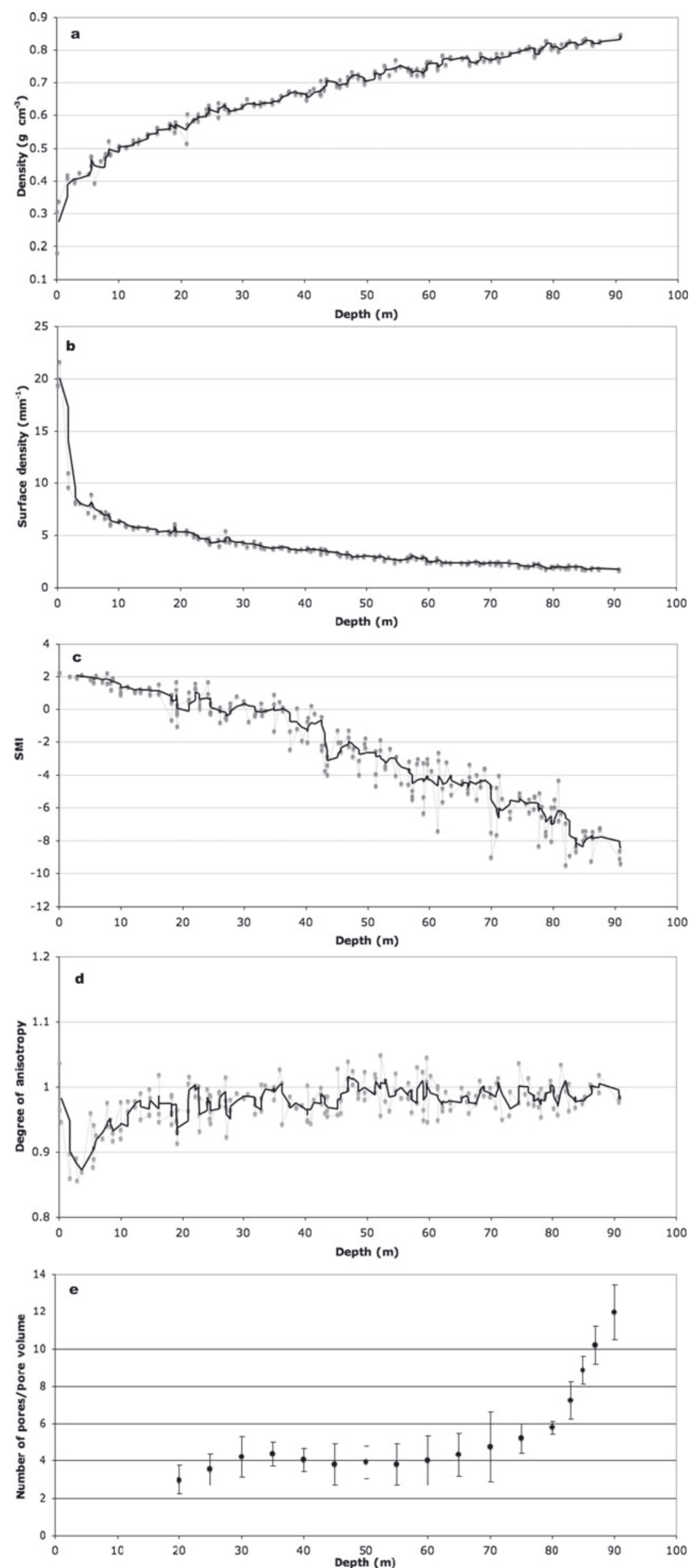

Fig. 5. Graphs of (a) density, (b) $S_{v^{\prime}}$ (c) SMI, (d) degree of anisotropy and (e) CPF. Black curves in (a-d) represent the running mean. In (e) the error bars are the standard deviations from at least three measurements. 
rate, indicating the slow and continuous rounding of pore spaces due to overburden pressure and isothermal mass transport processes. The degree-of-anisotropy values show a slightly vertical texture between 40 and $45 \mathrm{~m}$, and become more isotropic between 46 and $60 \mathrm{~m}$. These are small differences in the degree of anisotropy, but it is possible that they may be attributed to the surficial residence time of the snow layer (Rick and Albert, 2004; Hörhold and others, 2009). Rick and Albert (2004) showed that the microstructure of a material is a function of the structure that was developed at the surface and its length of exposure to temperaturegradient metamorphic processes. The longer the exposure time, the greater the vertical texture development, given a common initial state. It may be that the layers present between 40 and $45 \mathrm{~m}$ had short surficial residence times relative to those above $35 \mathrm{~m}$ and between 46 and $60 \mathrm{~m}$.

The deepest region, from 65 to $90 \mathrm{~m}$, shows another two levels of pore segregation. The first linear increase in CPF occurs from 65 to $80 \mathrm{~m}$, and the slope of that increase is comparable to the increase from 20 to $35 \mathrm{~m}$. The second section spans $80-90 \mathrm{~m}$. Here pore segregation occurs at a higher rate than in the regions above. Pores are segregated by the same means as above; however, overburden pressure should play a more integral role at this depth, which could influence the compaction rate. The SMI values show a value of -9 , and the degree of anisotropy shows an approximate value of 1 at $90 \mathrm{~m}$. This indicates that the structure is one of a majority of rounded pore spaces dispersed evenly throughout the specimens.

Near both 70 and $81 \mathrm{~m}$, there are a few specimens that exhibit a structure similar to those we see at $90 \mathrm{~m}$. They have relatively low SMI, and a high $\mathrm{CPF}$ index in comparison with the surrounding values. In addition, these areas have degreeof-anisotropy values with relatively small deviations from a value of 1 . These are horizons that are primarily ice but contain isolated bubbles. If such horizons are laterally continuous across a large area, they could cause the lock-in zone as defined by Sowers and others (1992). J. Severinghaus (personal communication, 2009) determined independently from in situ firn-air measurements in the borehole that the onset of the lock-in zone occurred at $69 \mathrm{~m}$ and that pore close-off occurred around $81 \mathrm{~m}$. Our microstructure measurements on the millimeter scale are consistent with his air-sampling measurements on a decimeter scale, and both confirm the existence of the lock-in zone.

\section{CONCLUSIONS}

A combination of SEM techniques including EDS and EBSPs, and X-ray micro-CT were used to perform a complete microstructural characterization of selected fine-grained samples from the firn column at Summit, Greenland. SEM analysis showed that both soluble impurities and dust particles in the firn were largely in the grain interiors, while both $c$ - and a-axis pole figures show little evidence of a preferred orientation of the grains at any depth. The firn showed an increasingly anisotropic structure in the top $3 \mathrm{~m}$ due to vapor transport associated with dry-snow metamorphism. The anisotropy decreases below this level until at $\sim 20 \mathrm{~m}$ the firn structure is largely isotropic. In the near surface, the presence of stronger anisotropy in the firn at Hercules Dome, a high-accumulation site in Antarctica, than at Summit is a reflection of the fact that the sites have different accumulation rates and temperatures which causes enduring evidence of the structure of the firn. Closed-off pores are evident throughout the firn column, but the fraction is low until $\sim 65 \mathrm{~m}$, when it starts to rise, and pore close-off occurs at $\sim 81 \mathrm{~m}$. Ongoing work will further explore the nature of the firn as it impacts ice-core gas records and remotely sensed data.

\section{ACKNOWLEDGEMENTS}

This work was supported by US National Science Foundation (NSF) grants OPP-0821056, 0738975 and 0520445. The views and conclusions contained herein are those of the authors and should not be interpreted as necessarily representing official policies, either expressed or implied, of the NSF or the US Government. We thank C.P. Daghlian and S. Chen for helpful discussions and acknowledge useful suggestions from the reviewers.

\section{REFERENCES}

Albert, M.R., E.F. Shultz and F.E. Perron, Jr. 2000. Snow and firn permeability at Siple Dome, Antarctica. Ann. Glaciol., 31, 353-356.

Alley, R.B. 1987. Texture of polar firn for remote sensing. Ann. Glaciol., 9, 1-4.

Alley, R.B. 1988. Concerning the deposition and diagenesis of strata in polar firn. J. Glaciol., 34(118), 283-290.

Baker, I. and D. Cullen. 2002. The structure and chemistry of $94 \mathrm{~m}$ Greenland Ice Sheet Project 2 ice. Ann. Glaciol., 35, 224-230.

Baker, I., D. Cullen and D. Iliescu. 2003. The microstructural location of impurities in ice. Can. J. Phys., 81(1-2), 1-9.

Baker, I., D. Iliescu, R. Obbard, H. Chang, B. Bostick and C.P. Daghlian. 2005. Microstructural characterization of ice cores. Ann. Glaciol., 42, 441-444.

Barnes, P.R.F. and E.W. Wolff. 2004. Distribution of soluble impurities in cold glacial ice. J. Glaciol., 50(170), 311-324.

Barnes, P.R.F., R. Mulvaney, K. Robinson and E.W. Wolff. 2002. Observations of polar ice from the Holocene and the glacial period using the scanning electron microscope. Ann. Glaciol., 35, 559-566.

Bender, M., T. Sowers and E. Brook. 1997. Gases in ice cores. Proc. Natl Acad. Sci. USA (PNAS), 94(16), 8343-8349.

Blackford, J.R. 2007. Sintering and microstructure of ice: a review. J. Phys. D, 40(21), R355-R385.

Colbeck, S.C. 1983. Theory of metamorphism of dry snow. J. Geophys. Res., 88(C9), 5475-5482.

Coléou, C., B. Lesaffre, J.B. Brzoska, W. Ludwig and E. Boller. 2001. Three-dimensional snow images by X-ray microtomography. Ann. Glaciol., 32, 75-81.

Courville, Z.R., M.R. Albert, M.A. Fahnestock, L.M. Cathles and C.A. Shuman. 2007. Impacts of an accumulation hiatus on the physical properties of firn at a low-accumulation polar site. J. Geophys. Res., 112(F2), F02030. (10.1029/2005JF000429.)

Cullen, D. and I. Baker. 2001. Observation of impurities in ice. Microsc. Res. Tech., 55(3), 198-207.

Cullen, D. and I. Baker. 2002. Observation of sulfate crystallites in Vostok accretion ice. Mater. Character., 48(4), 263-269.

Davis, R.E., E.M. Arons and M.R. Albert. 1996. Metamorphism of polar firn: significance of microstructure in energy, mass and chemical species transfer. In Wolff, E.W. and R.C. Bales, eds. Chemical exchange between the atmosphere and polar snow. Berlin, etc., Springer-Verlag, 379-401. (NATO ASI Series I: Global Environmental Change 43.)

Dominé, F. and 6 others. 2003. Snow metamorphism as revealed by scanning electron microscopy. Microsc. Res. Tech., 62(1), $33-48$.

Dominé, F. and 7 others. 2008. Snow physics as relevant to snow photochemistry. Atmos. Chem. Phys., 8(2), 171-208. 
Flin, F., J.-B. Brzoska, B. Lesaffre, C. Coléou and R.A. Pieritz. 2003. Full three-dimensional modelling of curvature-dependent snow metamorphism: first results and comparison with experimental tomographic data. J. Phys. D, 36(10A), A49-A54.

Flin, F., J.-B. Brzoska, B. Lesaffre, C. Coléou and R.A. Pieritz. 2004. Three-dimensional geometric measurements of snow microstructural evolution under isothermal conditions. Ann. Glaciol., 38, 39-44.

Freitag, J., F. Wilhelms and S. Kipfstuhl. 2004. Microstructuredependent densification of polar firn derived from X-ray microtomography. J. Glaciol., 50(169), 243-250.

Heggli, M., E. Frei and M. Schneebeli. 2009. Snow replica method for three-dimensional X-ray microtomographic imaging. J. Glaciol., 55(192), 631-639.

Hildebrand, T. and P. Rüegsegger. 1997. Quantification of bone microarchitecture with the structure model index. Comput. Meth. Biomech. Biomed. Eng., 1(1), 15-23.

Hildebrand, T., A. Laib, R. Müller, J. Dequeker and P. Rüegsegger. 1999. Direct 3-D morphometric analysis of human cancellous bone: microstructural data from spine, iliac crest and calcaneus. J. Bone Mineral Res., 14(7), 1167-1174.

Hörhold, M.W., M.R. Albert and J. Freitag. 2009. The impact of accumulation rate on anisotropy and air permeability of polar firn at a high-accumulation site. J. Glaciol., 55(192), 625-630.

Iliescu, D. and I. Baker. 2008. Effects of impurities and their redistribution during recrystallization of ice crystals. J. Glaciol., 54(185), 362-370.

Iliescu, D., I. Baker and D. Cullen. 2002. Preliminary microstructural and microchemical observations of pond and river accretion ice. Cold Reg. Sci. Technol., 35(2), 81-99.

Iliescu, D., I. Baker and H. Chang. 2004. Determining the orientations of ice crystals using electron backscatter patterns. Microsc. Res. Tech., 63(4), 183-187.

Kaempfer, T.U., M. Schneebeli and S.A. Sokratov. 2005. A microstructural approach to model heat transfer in snow. Geophys. Res. Lett., 32(21), L21503. (10.1029/2005GL023873.)

Kerckhofs, G., J. Schrooten, T. van Cleynenbreugel, S.V. Lomov and M. Wevers. 2008. Validation of x-ray microfocus computed tomography as an imaging tool for porous structures. Rev. Sci. Instr., 79(1), 013711. (10.1063/1.2838584.)

Li, L., P. Gaiser, M.R. Albert, D.G. Long and E.M. Twarog. 2008. WindSat passive microwave polarimetric signatures of the
Greenland Ice Sheet. IEEE Trans. Geosci. Remote Sens., 46(9), 2622-2631.

Lomonaco, R.W., I. Baker and S. Chen. 2008. Preliminary results on the characterization of firn using SEM and Micro CT. In Proceedings of the 65th Annual Eastern Snow Conference, 28-30 May, 2008, Fairlee (Lake Morey), Vermont, USA. Hanover, NH, US Army Cold Regions Research and Engineering Laboratory, 359-364.

Lomonaco, R.W., S. Chen and I. Baker. 2009. Characterization of porous snow with SEM and Micro CT. Microsc. Microanal., 15(S2), 1110-1111.

Ludwig, W. and 7 others. 2009. Three-dimensional grain mapping by $\mathrm{x}$-ray diffraction contrast tomography and the use of Friedel pairs in diffraction data analysis. Rev. Sci. Instr., 80(3), 033905. (10.1063/1.3100200.)

Lundy, C.C., M.Q. Edens and R.L. Brown. 2002. Measurement of snow density and microstructure using computed tomography. J. Glaciol., 48(161), 312-316.

Obbard, R., D. Iliescu, D. Cullen and I. Baker. 2003. SEM/EDS comparison of polar and seasonal temperate ice. Microsc. Res. Tech., 62(1), 49-61.

Obbard, R., I. Baker and K. Sieg. 2006. Using electron backscatter diffraction patterns to examine recrystallization in polar ice sheets. J. Glaciol., 52(179), 546-557.

Rick, U.K. and M.R. Albert. 2004. Microstructure and permeability in the near-surface firn near a potential US deep-drilling site in West Antarctica. Ann. Glaciol., 39, 62-66.

Schneebeli, M. and S.A. Sokratov. 2004. Tomography of temperature gradient metamorphism of snow and associated changes in heat conductivity. Hydrol. Process., 18(18), 3655-3665.

Schwander, J., B. Stauffer and A. Sigg. 1988. Air mixing in firn and the age of the air at pore close-off. Ann. Glaciol., 10, 141-145.

Schwander, J., T. Sowers, J.M. Barnola, T. Blunier, A. Fuchs and B. Malaizé. 1997. Age scale of the air in the Summit ice: implication for glacial-interglacial temperature change. J. Geophys. Res., 102(D16), 19,483-19,493.

Sowers, T., M. Bender, D. Raynaud and Y. Korotkevich. 1992. $\delta^{15} \mathrm{~N}$ of $\mathrm{N}_{2}$ in air trapped in polar ice: a tracer of gas transport in the firn and a possible constraint on ice age-gas age differences. J. Geophys. Res., 97(D14), 15,683-15,697.

Swinkels, F.B. and M.F. Ashby. 1980. A second report on sintering diagrams. Acta Metall., 29(2), 259-281.

MS received 8 April 2010 and accepted in revised form 18 March 2011 